DOI: 10.14451/2.137.7

\title{
ПЕРСПЕКТИВЫ И ОПАСНОСТЬ КРАУДФАНДИНГА
}

\author{
(c) 2019 Бортников Сергей Петрович \\ доктор юридических наук, доцент, директор института права \\ Самарский государственный экономический университет, Россия, Самара \\ E-mail: serg-bortnikov@yandex.ru
}

В статье рассматриваются особенности правового регулирования краудфандинга в России, а также в Великобритании и США. Институт исследуется в многообразии практик заключения контрактов: например, «долевые» краудфандеры инвестируют в акции, тогда как «поощрительные» краудфандеры получают продукцию производства авансом. Автор обращает внимание на то, что краудфандинг занимает положение между существующими режимами законодательства о ценных бумагах и законодательства о договорах с потребителями. Обращается внимание, что закон о защите прав потребителей в Великобритании (но не в США) вводит обязательные условия, которые препятствуют разделению рисков при вознаграждении в краудфандинге, в то время как закон США о ценных бумагах предписывает затратное раскрытие информации. В статье делается предположение, что краудфандинг при относительной легкости мобилизации средств неограниченного круга лиц, создает реальные риски для инвесторов, а классические методы регулирования рынка и эмиссии ценных бумаг и подходы потребительского права в исследуемых отношениях неэффективны.

Ключевые слова: краудфандинг, эмиссия, инвестор, потребитель,

Определение источников финансирования является также важнейшей задачей как в бизнесе, так и в муниципальных или межмуниципальных проектах. Применение механизмов софинансирования проектов и программ способствует повышению эффективности использования бюджетных средств в решении задач территориального развития. Определение источников мобилизации средств является важнейшей задачей не только для частного бизнеса, но и для публичных субъектов. Вместе с тем, важно, чтобы такие программы и проекты реализовывались не только муниципальными образованиями одного субъекта Российской Федерации, но и муниципальными образованиями разных субъектов РФ.

Одним из самых демократичных форм источников финансирования стартапов можно назвать «общественное финансирование» или «краудфандинг». Как следует из названия, речь идет о привлечении капитала от неопределенного числа лиц, каждое из которых, как правило, отдает небольшую сумму. Несмотря на длительную историю «общественного финансирования» проектов именно интернет снизил расходы на сбор средств таким образом, содействуя распространению информации о небольших проектах. Использование «крауд финансирования» растет экспоненциально [1]. Это чуть более шестой части суммы, полученной во всем мире за счет первоначальных публичных предложений (IPO) на фондовых рынках в том же году [2].

В нашей стране регулирование краудфандинга как самостоятельного института ранее не осуществлялась пока в августе 2019 года не был подписан закон [3]. В Великобритании Управление по финансовому поведению (Financial Conduct Authority (FCA)) за последние несколько лет разработало и обобщило несколько обзоров порядка применения «крауд финансирования» [4]. В США Комиссия по ценным бумагам и биржам (the Securities and Exchange Commission (SEC)) разработала регламент для розничной торговли крауд фандинга, который вступил в силу в мае 2016 года [5]. Еврокомиссия также активно стремится продвигать крауд финансирование в рамках плана ЕС по рынкам капитала [6].

Важное значение для привлечения инвестиций имеет информированность инвесторов. Алгоритм инвестиционной платформы по российскому законопроекту предполагает выражение согласия инвесторами, а также то, что они:

- ознакомлены с рисками,

- осознают высокорискованность сферы,

- принимают риски,

- готовы к потерям.

С другой стороны, информированный инвестор обладает навыками, знанием, информаци- 
ей. Часто влияние на выбор оказывает стадное поведение инвесторов, обусловленное приданием большого значения ненужной информации, ее искажение, игнорирование и пр. Это приводит к неправильному распределению ресурсов чрезмерному инвестированию в проекты, для которых перспективы слабы, и недостаточному инвестированию в проекты, для которых перспективы сильны,- что, конечно, снизит доходность для инвесторов и увеличит риски.

Обещание вознаграждения по краудфандингу.

Вознаграждение по краудфандингу представляет собой обещанную отгрузку продукции краудфандера в обмен на финансирование инвестором. Как и акционерное общество краудфандер заключает контракты непосредственно с финансирующими организациями и лицами. K сожаления, закон не определяет сущности и содержания отношений соинвесторов между собой, а также возможности конкуренции исков к краудфандеру между финансирующими организациями. Однако тот факт, что метод финансирования объединяет рынки капитала и продукции, означает, что взаимодействие между финансирующими организациями является совершенно иным, чем просто отношения соинвесторов.

Вознаграждение по краудфандингу почти аналогично предварительной оплате товара, за исключением того, что предприниматель обычно не раскрывает вопросы качества, перспектив поставки и пр. Наглядный пример такого распределения рисков можно найти в Условиях использования (Terms of Use), предлагаемых Kickstarter, ведущей платформой вознаграждения по краудфандингу. Они предусматривают, что дата поставки оценочное условие, а гарантия выполнения обязательства к этой дате отсутствует. Сроки исполнения обязательства к определенной в условиях краудфандинга дате могу меняться по мере работы краудфандера над проектом*. Что касается непоставки, то те же условия предусматривают, что создатель, который не в состоянии выполнить вознаграждение, может в качестве альтернативы «меня [и] их обязательства перед резервистами. Условиями пользования (Terms of Use) платформы Kickstarter определено, что стороны:
- обязаны разместить обновленную информацию о проделанной работе, порядке использования средств и о том, что мешает им завершить проект в соответствии с планом;

- упорно и добросовестно работать над тем, чтобы довести проект до наилучшего возможного завершения в сроки, которые определены предварительно;

- продемонстрировать, что они использовали средства надлежащим образом и приложили все разумные усилия для завершения проекта, как и было обещано;

- были честны и не допускали каких-либо существенных отступлений от своих обещаний инвесторам;

- обязуются вернуть любые оставшиеся средства тем, кто не получил вознаграждение (пропорционально объявленным суммам), или объяснить, как эти средства будут использованы для завершения проекта в какой-либо альтернативной форме.

Такой порядок устанавливает распределение рисков отличное от того, которое обычно встречается в договоре купли-продажи товаров, а также в процессе создания опытного образца или экспериментальной разработки. Такое распределение рисков принимается спонсорами в силу новаторского характера продукта. Спонсоры - это люди, которые с доверием относятся к предлагаемому продукту и, поскольку он является инновационным, не могут реализовать свое предпочтение в других местах. Для спонсоров мотивация финансирования именно данного продукта настолько сильна, что они готовы заплатить даже за менее чем определенную перспективу его получения.

Конечно, такое распределение рисков приводит к тому, что инвесторы рискуют нести расходы в процессе производства с неизвестным результатом, однако они полагаются на эффективность деятельности разработчика или, по крайней мере, надеются получить объяснение, почему результат не был достигнут. Такие условия обычно соответствуют договорам, касающихся совместного производства технологических инноваций. Опыт иностранных крауд площадок показывает, что непоставка на самом деле редка: менее пяти процентов учредителей не смогли исполнить свои обязательства по соз-

\footnotetext{
* Kickstarter, Terms of Use, clause 5 at https://www.kickstarter.com/terms-of-use. Условия данного положения явно предназначены для регулирования отношений не только между пользователями и платформой Kickstarter, но и между пользователями друг с другом.
} 
данию и поставке продукта, хотя более 75 процентов поставили продукт с нарушением срока, указанного в их предложениях.

Ключевым различием между вознаграждением и акционерной формой оформления финансирования является характер материального вознаграждения инвестора. При акционерной форме крайдфандинга стоимость окупаемости равна доходности по инвестициям, что зависит, в частности, от справедливой оценки акций.

Следует обратить внимание на опыт Великобритании и США в регулировании отношений краудфандинга. Регулирование крауд контрактов акционерного капитала актуально не только для внутреннего рынка, но, потенциально, и в качестве модели для других юрисдикций. Большая часть содержания законодательства Великобритании о ценных бумагах вытекает из законодательства ЕС, и более половины всех платформ «крауд-эмиссии», применяемых в ЕС, реализуются и в Великобритании [7]. В свою оче- редь, США, где находится крупнейшее в мире венчурное инвестиционное сообщество и рынки капитала, давно признаны лидером в предоставлении финансов для инноваций.

Тем не менее, Великобритания и США придерживаются совершенно разных подходов к регулированию крауд контрактов. Великобритания, используя изъятие из законодательства ЕС о ценных бумагах, разрешающее не раскрывать информацию при эмиссии как «исключение для небольших предложений», симулирует выпуск акций как форму заимствования, тогда как США, применяя обременительные правила раскрытия информации при выпуске акций - даже для небольших фирм - практически исключает данную форму из практики краудфандинга. Вместе с тем, вопросы выплаты вознаграждения по крауд обязательствам в Великобритании разрешаются в сфере действия правил о защите прав потребителей, чего в США попросту нет.

\section{Библиографический список}

1. Massolution, Crowdfunding Industry 2015 Report (2016). В России исследование по краудфандингу не проводились.

2. Y, EY Global IPO Trends 2015 4Q, 4 (2016).

3. Федеральный закон от 2 августа 2019 г. N 259-Ф3 «О привлечении инвестиций с использованием инвестиционных платформ и о внесении изменений в отдельные законодательные акты Российской Федерации» / Правовая система «Гарант» (обращение 22.11.2019).

4. FCA, Interim Feedback to the Call for Input to the Post-Implementation Review of the FCA's Crowdfunding Rules FS16/13 (2016). See also FCA, The FCA's Regulatory Approach to Crowdfunding over the Internet, and the Promotion of Non-Readily Realisable Securities by Other Media PS14/4 (2014).

5. SEC, 'Crowdfunding: Final Rule' (2015) 80 Federal Register 71388 (17 CFR Parts 200, 226, 232, 239, 240, 249, 269 and 274).

6. See European Commission, Action Plan on Building a Capital Markets Union COM(2015) 468 final, 30 September 2015, 7; European Commission, Crowdfunding in the EU Capital Markets Union SWD(2016) 154 final, 3 May 2016.

7. ESMA, Investment-Based Crowdfunding: Insights from Regulators in the EU ESMA/2015/856 Ann 1 (2015), 2.

8. Закон Самарской области от 09.11.2005 N 198-ГД (ред. от 06.02.2015) «О государственной поддержке инновационной деятельности на территории Самарской области» (принят Самарской Губернской Думой 25.10.2005) / Правовая система «Консультант Плюс» (обращение 22.11.2019).

9. European Commission, Published Results: Consultation on the Review of the Prospectus Directive / http:// ec.europa.eu/eusurvey/publication/prospectus-directive-2015?language=en. См. также: European Commission, Consultation Document: Review of the Prospectus Directive (February 2015) 4-6. 